\title{
Decreased embryonic survival of in-vitro fertilized oocytes in rats is due to retardation of preimplantation development
}

\author{
B. C. Vanderhyden and D. T. Armstrong \\ Departments of Physiology and Obstetrics and Gynecology, University of Western Ontario, London, \\ Canada N6A 5 A5
}

\begin{abstract}
Summary. Immature female rats $(60-65 \mathrm{~g})$ were injected with 4 i.u. PMSG on Day -2 and allocated to 3 groups. On the evening of Day 0, rats in Groups I and II were allowed to mate. Embryos were collected on Day 4 (Group I, control morulae) or Day 5 (Group II, control blastocysts) and were transferred into the oviduct or uterine horn of Day-4 pregnant recipient rats. On the transfer side of the recipients, the bursa had been peeled from around the ovary to prevent endogenous oocytes from entering the oviduct. For Group III, unmated donors were killed 65-67 h after PMSG injection. Ovulated oocytes recovered from the oviducts were fertilized in vitro and transferred 16-18 h later. Embryos developing from in-vitro fertilized (IVF) oocytes were recovered on Day 5, separated into morulae (Group IIIm) and blastocysts (Group IIIb) and transferred into Day-4 pregnant recipients similar to control embryos. Some embryos from each group were used to determine the mean number of cells/embryo. Embryo recipients were killed on Day 20.

After transfer, the development of IVF oocytes was retarded compared to control embryos. IVF morulae contained significantly fewer cells/embryo than did control morulae but were able to implant and grow to fetuses, in proportions similar to controls, if transferred into the oviduct of the recipients.

These results suggest that the developmental potential of rat oocytes fertilized in vitro is limited due to asynchrony between the embryo and the uterine environment at the time of implantation, rather than possible defects incurred by the oocyte during the fertilization procedure.
\end{abstract}

Keywords: in-vitro fertilization; embryo development; implantation; asynchronous transfer; rat

\section{Introduction}

Techniques for in-vitro fertilization and embryo transfer have become established as treatment of some causes of human infertility. Most oocytes retrieved can be successfully fertilized in vitro but, even though several embryos are returned to the women, usually less than $25 \%$ of embryo transfers result in full-term pregnancy (Grobstein et al., 1983; Jones et al., 1984; Wood et al., 1985). Animal models have been developed to facilitate the study of embryonic and fetal development of transferred embryos resulting from fertilization in vitro (Noyes, 1952; Toyoda \& Chang, 1974; Walton \& Armstrong, 1983). In these models early investigations indicated that, after transfer, oocytes fertilized in vitro were capable of development to full-term fetuses in the low proportions similar to those seen in humans. In addition, it was demonstrated that many embryos from in-vitro fertilized oocytes were slower to advance to the blastocyst stage than were those from oocytes fertilized in vivo (Vanderhyden et al., 1986a). When an embryo is delayed in development, implantation may or may not occur, depending on the degree of asynchrony in development of the embryo and the uterine environment 
(Dickmann \& Noyes, 1960). Therefore, the slower rate of development of the in-vitro fertilized embryos may be the cause of unsuccessful implantation. The present studies were undertaken to determine whether the ability of in-vitro fertilized oocytes to produce full-term fetuses could be increased by providing them with additional time for preimplantation development.

\section{Materials and Methods}

Animals. Immature female Sprague--Dawley rats, mature male Sprague-Dawley rats and mature female Long-Evans rats were obtained from Charles River Canada, Inc., St Constant, Quebec. They were housed in air-conditioned quarters with free access to food and water. Lighting was provided for $14 \mathrm{~h}$ daily, but the timing of the period of illumination was altered so that ovulation occurred in the early afternoon. All times cited in the text refer to the diurnal cycle of the animals, i.e. $00: 00 \mathrm{~h}$ refers to the midpoint of the dark period (equivalent to midnight) and 12:00 $\mathrm{h}$ is the midpoint of the light period (equivalent to noon).

To clarify the sequence of events of the experimental protocol, the timing of the events is summarized in Fig. 1.

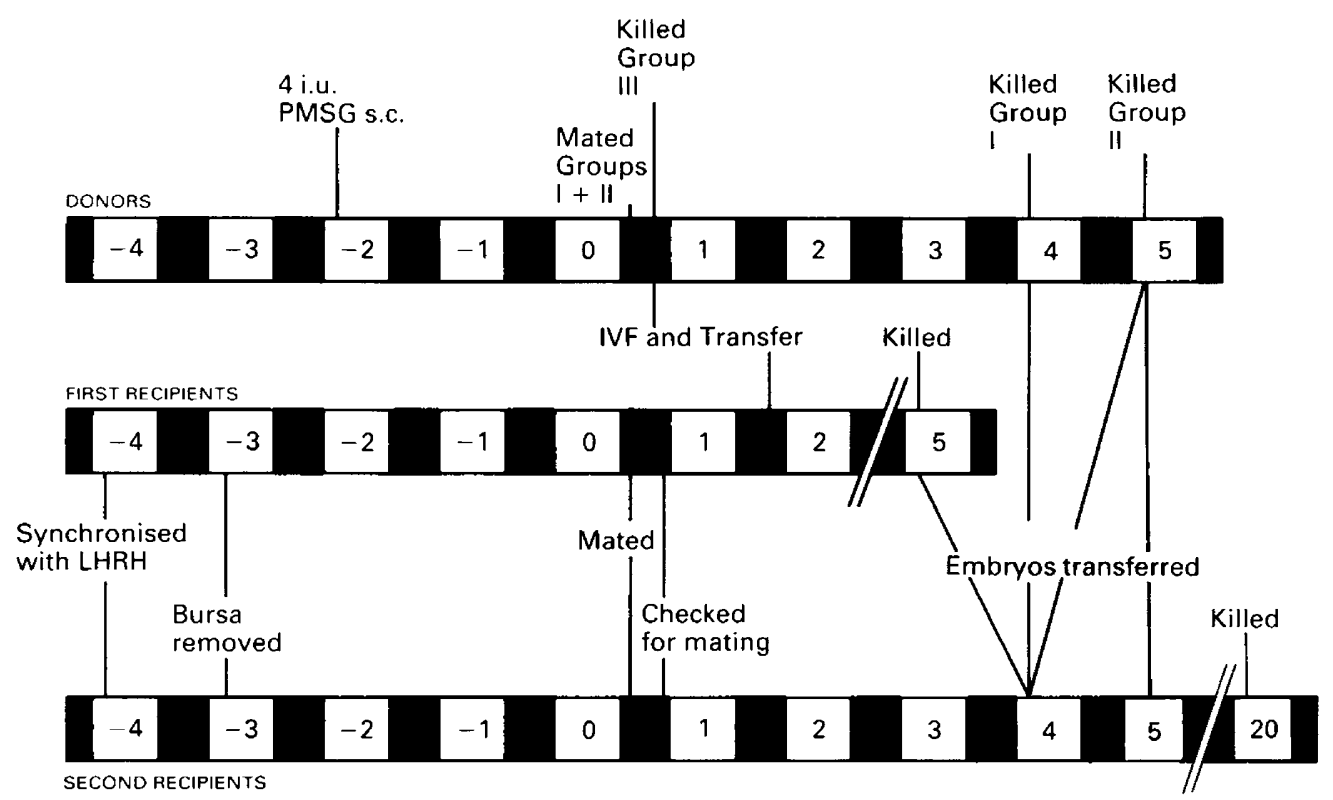

Fig. 1. Diagram of the procedure used for embryo transfers. Light and dark areas indicate periods of light and dark, respectively. The numbers refer to the day of the experiment (Day $1=$ first day of pregnancy).

Donors. At a body weight of $60-65 \mathrm{~g}(\sim 26$ days old), the immature rats were treated with 4 i.u. PMSG (Equinex: Ayerst, Montreal) at $08: 00 \mathrm{~h}$ on Day -2 (Day $0=$ day of mating). On Day 0 the rats were randomly allocated to 3 groups. Rats in the group for transfer of Day-4 control embryos (Group I) and of Day-5 control embryos (Group II) were caged with males of proven fertility from 20:00 h on Day 0 to 04:00 h on Day 1, when they were assessed for mating. The presence of a copulatory plug and/or spermatozoa in the vaginal smear was taken as evidence of insemination. Mated donors were killed at 20:00-22:00 h on Day 4 (Group I) or at 08:00-10:00 h on Day 5 (Group II). Using a 30-gauge needle, the embryos were flushed from the oviducts and/or uterine horns with Dulbecco's phosphate-buffered saline (DPBS; Gibco Laboratories, Grand Island, NY, U.S.A) containing $5 \%(\mathrm{v} / \mathrm{v})$ heat-inactivated, charcoal-treated rat serum. Embryos were collected and transferred immediately to mated recipients (see below).

Rats in the group for transfer of oocytes fertilized in vitro (Group III) were killed on Day 1 between 01:00 and 03:00 $\mathrm{h}$. The oviducts were dissected out in DPBS and the swollen ampullae were torn open with fine forceps to allow the oocytes to escape. The oocytes were then fertilized in vitro as described previously (Vanderhyden et al., 1986a), with fertilization rates ranging from 85 to $100 \%$. Fertilization was assessed by phase-contrast microscopy $14-16 \mathrm{~h}$ after insemination and only zygotes with 2 pronuclei and 1 sperm tail were transferred to mated recipients. 
Recipients. The cycles of the female Long-Evans rats were synchronized with $40 \mu \mathrm{g}$ luteinizing hormone-releasing hormone (LHRH) agonist (des-Gly ${ }^{10}$, D-Ala ${ }^{6}$, L-ProNHEt $^{9}$ LHRH; Sigma, St Louis, MO, U.S.A.) as described previously (Walton \& Armstrong, 1983). At 3-14 days before the day of mating, the rats were anaesthetized with tribromoethanol solution $(2 \% \mathrm{v} / \mathrm{v}, 0.01 \mathrm{ml} / \mathrm{g}$ body weight, i.p.) and, via a lateral incision, the ovarian bursa was peeled back from around the left ovary of each recipient (Vanderhyden et al., 1986b). This procedure eliminates the pick-up of ovulated oocytes by the oviduct and, therefore, produces unilateral pregnancy in $93 \%$ of recipient rats. In later stages of gestation, fetal eye colour was used as additional verification of the source of embryo.

At $20: 00 \mathrm{~h}$ of Day 0 , the recipient rats were caged with males of proven fertility. They were assessed for mating at 04:00 h on Day 1 and only mated rats were subsequently used. Some of the mated rats were used as Day-1 recipients for oocytes that had been fertilized in vitro. The remaining rats were left until Day 4 of pregnancy at which time they became recipients of Day-4 or Day- 5 embryos (see below).

Collection and transfer of embryos. Oocytes fertilized in vitro were transferred at 20:00-23:00 h on Day 1. The recipient rats were anaesthetized with tribromoethanol solution and the bursa-free (left) ovary was withdrawn through a lateral incision. Using a finely drawn heat-polished pipette, $4-5$ zygotes were transferred to the infundibulum of the left oviduct (transfer oviduct) of each recipient. With the bursa peeled from around the ovary, the oviduct would contain only transferred zygotes; the contralateral side, with the bursa intact, served as a control. Some of these recipients were allowed to reach Day 20 of gestation, at which time the transferred zygotes were assessed for their ability to develop to near-term fetuses. At 06:00-08:00 h on Day 5 the remaining recipients were killed and both the transfer and the control oviducts and uterine horns were removed and flushed with DPBS. Previous experiments have indicated that half of the embryos developing from in-vitro fertilized oocytes and collected at this time are morulae, while the remaining embryos are at the blastocyst stage (Vanderhyden et al., 1986a). Therefore, when the embryos were collected in the current experiment, they were divided into 2 groups, depending on their stage of development (Group IIIm $=$ morulae; Group IIIb = blastocysts). Four or 5 embryos were transferred into the left oviduct or uterine horn of the Day-4 pregnant recipients. Control embryos from the Day-4 (Group I) and Day-5 (Group II) donor rats were collected and transferred in a similar manner. As an additional control, some of the Day-5 Group-III embryos were transferred into the uterine horn of Day-5 pregnant recipients. Oviducal transfers were performed as described earlier. For uterine transfers a small portion of the uterine horn near the uterotubular junction was drawn through an incision by pulling the fat pad. A small hole was made near the top of the horn with the point of an 18-gauge needle. The transfer pipette was inserted into this hole and the embryos were gently expelled.

Stage of embryo development. To determine the stage of embryo development more accurately, some of the embryos from each group were used for cell counting. Using a method described by Fujimoto et al. (1975), embryos were fixed in a solution of methanol:glacial acetic acid:deionized water $(4: 1: 3$, by vol.) and placed on a glass slide. The cells were separated by allowing drops of a methanol:glacial acetic acid $(3: 1, \mathrm{v} / \mathrm{v})$ solution to fall on the embryo from a height of $10-12 \mathrm{~cm}$. The embryos were then stained with haematoxylin and the number of cells in each embryo was counted.

Collection of fetuses. The recipient rats were killed at 08:00 h on Day 20. The number of fetuses and the total fetal weights and placental weights were recorded for the control and transfer horns of each rat. The number and size of resorption sites in each horn were also noted.

Statistical analyses. The proportions of oocytes recovered as Day-5 embryos were compared using $\chi^{2}$ analyses with Yates' correction. The proportions of oocytes recovered as fetuses or resorption sites were compared using the RXC test for independence and $\chi^{2}$ analyses. Comparisons of the mean number of cells/embryo for each group and comparisons of mean fetal and placental weights in each group were made using one-way analysis of variance with Bartlett's test for homogeneity of variance and Duncan's new multiple range test (Steel \& Torrie, 1980).

\section{Results}

As in experiments described previously (Vanderhyden et al., 1986a), the control embryos produced by in-vivo fertilization and recovered on Day 5 were primarily at the blastocyst stage of development (Table 1). In contrast, half of the embryos developing from in-vitro fertilized oocytes were still at the morula stage, indicating that the development of these embryos was retarded compared with those in the control horn.

Embryos from each group were collected and the number of cells/embryo was determined (Table 2). As would be expected, Day- 5 control embryos had a significantly greater mean number of cells/embryo than did the Day-4 control embryos $(P<0.01)$. Blastocysts derived from in-vitro fertilized oocytes contained a mean number of cells/embryo that was not significantly different from that of the control blastocysts or morulae. In agreement with the morphologically evident retardation in development of the morulae from in-vitro fertilized oocytes, these embryos also 
Table 1. Stage of development of in-vitro fertilized rat oocytes on Day 5 after transfer to recipients

\begin{tabular}{lcc}
\hline & $\begin{array}{c}\text { Stage of } \\
\text { development }\end{array}$ & $\begin{array}{c}\text { \% (of total no.) of } \\
\text { zygotes recovered }\end{array}$ \\
\hline Control horn & Blastocyst & $80 \cdot 9(444)^{\mathrm{a}}$ \\
Transfer horn & Morula & $19 \cdot 1(444)^{\mathrm{b}}$ \\
& Blastocyst & $51 \cdot 1(377)^{\mathrm{c}}$ \\
& Morula & $48 \cdot 8(377)^{\mathrm{c}}$ \\
\hline
\end{tabular}

$\overline{\text { a,b,c } V \text { alues with different superscripts are significantly different }}$ $(P<0.001)$.

showed a significantly lower mean number of cells/embryo compared to the other three groups $(P<0.01)$.

Some of the in-vitro fertilized zygotes transferred on Day 1 were assessed on Day 20 of gestation for their ability to develop to near-term fetuses without an intermediate transfer. A large proportion of the transferred zygotes $(47 \cdot 1 \% ; n=119)$ became viable fetuses with $17 \cdot 6 \%$ of the zygotes being recovered as resorption sites. This success rate is comparable to the proportions of Day- 5 blastocysts derived from in-vitro fertilized oocytes (Group III) that were recovered as fetuses after synchronous transfer into Day-5 pregnant recipients $(42.9 \%, n=42)$. The transfer of Group-III morulae into Day- 5 recipients showed a significantly lower success rate of only $9.3 \%(n=43)$. The proportions of Group-III embryos recovered as resorption sites were $14 \cdot 3 \%$ for transferred blastocysts and $23.5 \%$ for morulae.

Table 2. Mean number of cells per embryo at time of transfer into Day 4 pregnant recipient rats

\begin{tabular}{llll}
\hline Group & \multicolumn{1}{c}{ Embryo } & Source & $\begin{array}{c}\text { Mean }( \pm \text { s.e.m.) no. of } \\
\text { cells/embryo }(n)\end{array}$ \\
\hline I & Day-4 morula & Control & $22 \cdot 4 \pm 0.6(57)^{\mathrm{a}}$ \\
II & Day-5 blastocyst & Control & $26 \cdot 1 \pm 0 \cdot 8(39)^{\mathrm{b}}$ \\
IIIm & Day-5 morula & IVF & $17.9 \pm 1 \cdot 1(21)^{\mathrm{c}}$ \\
IIIb & Day-5 blastocyst & IVF & $24.5 \pm 0.8(25)^{\mathrm{b}}$ \\
\hline
\end{tabular}

a,b,c Values with different superscripts are significantly different $(P<0.01)$.

Table 3. Number of embryos recovered as fetuses and resorption sites (R.S.) on Day 20 after transfer into Day-4 pregnant recipient rats

\begin{tabular}{|c|c|c|c|c|c|c|}
\hline \multirow[b]{3}{*}{ Group } & \multirow[b]{3}{*}{ Embryo } & \multirow[b]{3}{*}{ Source } & \multicolumn{4}{|c|}{$\%$ (of total no.) of transferred embryos recovered } \\
\hline & & & \multicolumn{2}{|c|}{ Into oviduct } & \multicolumn{2}{|c|}{ Into uterus } \\
\hline & & & Fetuses & R.S. & Fetuses & R.S. \\
\hline I & Day-4 morula & Control & $27 \cdot 4^{a \cdot x}$ & $3 \cdot 2(62)$ & $66 \cdot 1^{a, y}$ & $13.8(65)$ \\
\hline II & Day-5 blastocyst & Control & $40 \cdot 7^{a, x}$ & $8 \cdot 6(81)$ & $54 \cdot 6^{a, x}$ & $15 \cdot 6(77)$ \\
\hline IIIm & Day-5 morula & IVF & $26 \cdot 7^{a, x}$ & $12 \cdot 9(60)$ & $18 \cdot 4^{b \cdot x}$ & $18.4(49)$ \\
\hline IIIb & Day- 5 blastocyst & IVF & $34 \cdot 1^{a, x}$ & $13.4(82)$ & $45 \cdot 4^{a, x}$ & $13.6(44)$ \\
\hline
\end{tabular}

For fetuses within columns, values with different alphabetical superscripts $(a, b)$ are significantly different $(P<0.01)$; within rows values with different superscripts $(\mathrm{x}, \mathrm{y})$ are significantly different $(P<0.001)$. 
Table 4. Mean fetal and placental weights on Day 20 of gestation in rats after transfer of embryos on Day 4

\begin{tabular}{|c|c|c|c|c|}
\hline \multirow[b]{2}{*}{ Group } & \multicolumn{2}{|c|}{ Fetal weight (g) } & \multicolumn{2}{|c|}{ Placental weight (mg) } \\
\hline & Control side & Transfer side & Control side & Transfer side \\
\hline \multicolumn{5}{|c|}{ I Control morula } \\
\hline Oviduct & $2.09 \pm 0.04(13)$ & $1.97 \pm 0.07$ & $531 \pm 13(13)$ & $541 \pm 45$ \\
\hline Uterus & $2 \cdot 01 \pm 0 \cdot 05(12)$ & $1.99 \pm 0.05(11)$ & $470 \pm 15(12)$ & $465 \pm 16(11)$ \\
\hline \multicolumn{5}{|c|}{ II Control blastocyst } \\
\hline Oviduct & $2.03 \pm 0.05(16)$ & $1.95 \pm 0.05(11)$ & $492 \pm 14(16)$ & $497 \pm 24(11)$ \\
\hline Uterus & $1.98 \pm 0.04(15)$ & $2 \cdot 14 \pm 0.08(15)$ & $478 \pm 11(15)$ & $486 \pm 17(15)$ \\
\hline \multicolumn{5}{|c|}{ IIIm IVF morulae } \\
\hline Oviduct & $2.02 \pm 0.03(15)$ & $1.91 \pm 0.07$ & $457 \pm 12(15)$ & $441 \pm 15$ \\
\hline Uterus & $2.01 \pm 0.06(11)$ & $2 \cdot 15 \pm 0 \cdot 10$ & $495 \pm 14(11)$ & $499 \pm 30$ \\
\hline \multicolumn{5}{|c|}{ IIIb IVF blastocyst } \\
\hline Oviduct & $1.99 \pm 0.05(14)$ & $2.02 \pm 0.07(10)$ & $454 \pm 13(12)$ & $526 \pm 29(10)$ \\
\hline Uterus & $2.08 \pm 0.06$ & $2 \cdot 15 \pm 0 \cdot 10$ & $519 \pm 34$ & $492 \pm 19$ \\
\hline
\end{tabular}

Values are mean \pm s.e.m. for the number of rats in parentheses.

The proportion of embryos recovered as near-term fetuses after transfer into Day-4 recipients is summarized in Table 3. Embryos developing from in-vitro fertilized and control oocytes were equally capable of implantation and fetal development when transferred into the oviducts of the recipients. However, the survival of the Group-III morulae after transfer into the recipient uterine horn was significantly less than that of Group-III blastocysts or the control morulae or blastocysts $(P<0.01)$, with no significant differences between the last three groups. Despite the poor success rate of Group-III morulae when transferred into the uterine horn of Day-4 recipients, these embryos did better than those morulae transferred into Day -5 recipients. Within Groups I, II and IIIb, the embryos were noticeably more capable of implantation and fetal development when transferred into the uterine horn rather than into the oviduct of the Day-4 recipient, although this improvement was statistically significant $(P<0.001)$ only in Group I. There was no significant difference in the ability of Group-III morulae to develop into fetuses after transfer into the oviduct or uterus.

The proportion of transferred embryos recovered as resorption sites in the transfer uterine horn on Day 20 is also summarized in Table 3. There were no significant differences among the 4 groups in the incidence of resorption sites following embryo transfer into the oviducts or the uterine horns. In addition, the proportion of embryos recovered as resorption sites after oviducal transfer was not significantly different from that of embryos recovered after uterine transfer within each group. Most resorption sites $(92 \%)$ were $<1 \mathrm{~cm}$ in diameter.

The mean fetal and placental weights for each group are summarized in Table 4. Within each treatment there was no significant difference between the mean fetal or placental weights of the transfer side compared with those of the control side.

\section{Discussion}

These experiments have examined the possibility that low embryonic survival of in-vitro fertilized oocytes is due to asynchronous development of the embryo and the uterine environment at the time of implantation. In previous experiments (Vanderhyden et al., 1986a) it was determined that in-vitro fertilized oocytes showed a delay in development such that, at 08:00 h on Day 5, half of the embryos were at the morula stage whereas most control embryos were blastocysts. This observation has been confirmed in the current experiments. It has been demonstrated that in-vitro development of mouse l-cell embryos to the blastocyst stage is delayed compared to development within the reproductive 
tract of pregnant (Bowman \& McLaren, 1970; Harlow \& Quinn, 1982), pseudopregnant or immature (Papaioannou \& Ebert, 1986) females. Although the oocytes in the present experiments were in culture for only $16-18 \mathrm{~h}$, it is possible that this period in vitro was sufficient to cause the delay in the development of these oocytes. A previous study has indicated, however, that a $10-12 \mathrm{~h}$ period of in-vitro culture before transfer had no detrimental effect on the ability of in-vivo fertilized oocytes to develop to Day-20 fetuses (Vanderhyden et al., 1986a). The delay in embryonic development in this experiment was quantified by counting the number of cells in embryos from each group. The mean number of cells in the Day-5 control blastocysts $(26 \cdot 1 \pm 0 \cdot 8)$ agrees well with that found in a study by Surani (1975) with a value of $27.52 \pm 4.0$. The lower mean number of cells in the GroupIII morulae strongly supports the suggestion that fertilization in vitro and/or the time in vitro associated with it caused a delay in the development of the embryos that ultimately became detrimental at the time of implantation.

The experiments reported here demonstrate the increased ability of some Group-III embryos to develop to fetuses if given additional time for preimplantation growth. The transfer of Group-III morulae into the oviduct resulted in a proportion of embryos developing to fetuses that is similar to the other three groups. Transfer of these embryos into the uterus, however, is not conducive to implantation and subsequent fetal growth. Furthermore, transfers of Group-III morulae into Day-5 uterine horns, i.e. not given additional time for preimplantation growth, result in a rate of survival significantly less than that for transfers into Day-4 recipients. These results lead to a number of possible explanations: (1) that the oviduct is a more favourable environment for embryos retarded in development; (2) that the younger embryos are too delayed in development to catch up with the state of the uterus; or (3) that the uterus is actually a hostile environment, less tolerant of embryos that are not at the appropriate stage of development.

Early studies in rabbits (Chang, 1952) and mice (Bowman \& Roberts, 1958) demonstrate the ability of nearly all ovulated oocytes to be fertilized and develop normally in the oviduct. A significant proportion of the reproductive losses in these species results from functional defects occurring around the time of implantation. Implantation takes place only when the embryo and the endometrium have simultaneously reached specific stages in their development (Noyes \& Dickmann, 1960, 1961; Dickmann \& Noyes, 1960; Noyes et al., 1963). Transferred embryos that were 1 day younger than the recipient uterus developed at the usual rate until the 5 th day of pregnancy and then degenerated rapidly and failed to implant. It was concluded that the uterine environment undergoes changes in the afternoon of Day 5, becoming detrimental to younger embryos, but stimulating Day-5 blastocysts in such a way that they elicit the decidual reaction. These results possibly explain the poor survival of the Group-III morulae when transferred directly into the uterus in the current experiments.

In contrast to transfers into the uterus, oviducal transfers may offer some advantages to the embryo, particularly if it is delayed in development. With asynchronous development of the embryo and the recipient uterine environment, there appears to be a wider margin of safety for oviducal than for uterine transfers. Noyes \& Dickmann (1961) determined that embryos 1-5 days of age were capable of surviving transfer to the oviduct, while only 3- to 5-day-old embryos survived transfer to the uterus. While the oviduct may offer advantages when the exact stage of development of the donor embryos is uncertain (as it was with the Group-III embryos), the uterus obviously has its own benefits when receiving embryos of more appropriate stages: slightly larger percentages of embryos survived transfer to the uterus than to the oviduct. This is in agreement with the work done by Noyes \& Dickmann (1961).

It is tempting to extrapolate the results of these experiments to the human programmes for in-vitro fertilization. In these programmes, 4-cell embryos are commonly transferred into the uterus 2 days after follicular aspiration. In natural cycles, the blastocyst normally enters the uterus 3-4 days after ovulation (Jones, 1984). Therefore, an embryo is being transferred into a uterine environment which may be 1-3 days advanced in relation to the development of the embryo; this difference may be sufficient to prevent implantation. Testart (1987) has shown a high pregnancy rate when transfers were performed with frozen-thawed embryos coming from in-vitro fertilization cycles in which 
pregnancy did not occur after transfer of fresh embryos. He suggests that the unsuccessful in-vitro fertilization cycles were the consequence of an unfavourable uterine environment resulting from the ovarian stimulation procedures and that an increase in the success rate of in-vitro fertilization can be predicted if embryos are frozen and stored to be transferred at a later cycle into a more normal uterine environment not influenced by exogenous hormonal stimulation. In contrast, there is some evidence to suggest that the advanced endometrium may be more conducive to implantation, regardless of the state of development of the embryo (Jones, 1984). Clearly more information about the mechanism of implantation in humans is necessary before comparisons can be made.

In conclusion, some embryos derived from in-vitro fertilized oocytes have a slower rate of development that appears to be detrimental at the time of implantation. If given additional time for preimplantation development, many of these embryos are capable of implantation and normal fetal growth. The developmental potential of transferred in-vitro fertilized rat oocytes therefore appears to be limited, at least partly, by the asynchrony between the embryo and the uterine environment, rather than by a defect in the oocyte caused by the fertilization procedure.

This work was supported by the M.R.C. of Canada; D.T.A. is a Career Investigator of the M.R.C. We thank Ms A. Rouleau and Ms J. Rutledge for excellent technical assistance and Dr T. G. Kennedy for helpful discussions and advice.

\section{References}

Bowman, P. \& McLaren, A. (1970) Cleavage rate of mouse embryos in vivo and in vitro. J. Embryol. exp. Morph. 24, 203-207.

Bowman, J.C. \& Roberts, R.C. (1958) Embryonic mortality in relation to ovulation rate in the house mouse. J. exp. Biol. 35, 138-143.

Chang, M.C. (1952) An experimental analysis of female sterility in the rabbit. Fert. Steril., 3, 251-262.

Dickmann, Z. \& Noyes, R.W. (1960) The fate of ova transferred into the uterus of the rat. J. Reprod. Fert. 1, 197-212.

Fujimoto, S., Passantino, T.J., Koenczoel, I. \& Segal, S.J. (1975) A simplified method for chromosome preparations of the rat preimplantation embryos. Cytologia 40, 469-475.

Grobstein, C., Flower, M. \& Mendeloff, J. (1983) External human fertilization: an evaluation of policy. Science, N.Y. 222, 127-133.

Harlow, G.M. \& Quinn, P. (1982) Development of preimplantation mouse embryos in vivo and in vitro. Aust. J. biol. Sci. 35, 187-193.

Jones, G.S. (1984) Update on in vitro fertilization. Endocrine Reviews 5, 62-75.

Jones, H.W., Acosta, A.A., Andrews, M.C., Garcia, J.E., Jones, G.S., Mayer, J., McDowell, J.S., Rosenwaks, Z., Sandow, B.A., Veeck, L.L. \& Wilkes, C.A. (1984) Three years of in vitro fertilization at Norfolk. Fert. Steril. 42, 826-834.

Noyes, R.W. (1952) Fertilization of follicular ova. Fert. Steril, 3, 1-12.

Noyes, R.W. \& Dickmann, Z. (1960) Relationship of ovular stage to endometrial development. J. Reprod. Fert. 1, 186-196.

Noyes, R.W. \& Dickmann, Z. (1961) Survival of ova transferred into the oviduct of the rat. Fert. Steril. 12, 67-79.
Noyes, R.W., Dickmann, Z., Doyle, L.L. \& Gates, A.H. (1963) Ovum transfers, synchronous and asynchronous, in the study of implantation. In Delayed Implantation, pp. 197-211. Ed. A. C. Enders. University of Chicago Press, Chicago.

Papaioannou, V.E. \& Ebert, K.M. (1986) Development of fertilized embryos transferred to oviducts of immature mice. J. Reprod. Fert. 76, 603-608.

Steel, R.G.D. \& Torrie, J.H. (1980) Principles and Procedures of Statistics. McGraw-Hill, Inc., New York.

Surani, M.A.H. (1975) Zona pellucida denudation, blastocyst proliferation and attachment in the rat. $J$. Embryol. exp. Morph. 33, 343-353.

Testart, J. (1987) Evidence of uterine inadequacy to egg implantation in stimulated in vitro fertilization cycles. Fert. Steril. 47, 855-857.

Toyoda, Y. \& Chang, M.C. (1974) Fertilization of rat eggs in vitro by epididymal spermatozoa and the development of eggs following transfer. J. Reprod. Fert. 36, 9-22.

Vanderhyden, B.C., Rouleau, A., Walton, E.A. \& Armstrong, D.T. (1986a) Increased mortality during early embryonic development after in-vitro fertilization of rat oocytes. J. Reprod. Fert. 77, 401-409.

Vanderhyden, B.C., Rouleau, A. \& Armstrong, D.T. (1986b) Effect of removal of the ovarian bursa of the rat on infundibular retrieval and subsequent development of ovulated oocytes. J. Reprod. Fert. 77, 393-399.

Walton, E.A. \& Armstrong, D.T. (1983) Oocyte normality after superovulation in immature rats. J. Reprod. Fert. 67, 309-314.

Wood, C., McMaster, R., Rennie, G., Trounson, A. \& Leeton, J. (1985) Factors influencing pregnancy rates following in vitro fertilization and embryo transfer. Fert. Steril. 43, 245-250.

Received 10 December 1987 